Article

\title{
A Normal Cloud Model-Based Method for Water Quality Assessment of Springs and Its Application in Jinan
}

\author{
Xintong Wang ${ }^{1}$, Weimin Yang ${ }^{1,2, *}$, Zhenhao $\mathrm{Xu}^{1,2,3, *}$, Jie Hu ${ }^{1}$, Yiguo Xue ${ }^{1}$ and Peng Lin ${ }^{1}$ \\ 1 Geotechnical \& Structural Engineering Research Center, Shandong University, Jinan 250061, China; \\ wangxintong0722@163.com (X.W.); hjxz1996@163.com (J.H.); xieagle@163.com (Y.X.); \\ sddxytlp@163.com (P.L.) \\ 2 School of Qilu Transportation, Shandong University, Jinan 250061, China \\ 3 SinoProbe Center - China Deep Exploration Center, Chinese Academy of Geological Sciences, \\ Beijing 100037, China \\ * Correspondence: weimin.yang@sdu.edu.cn (W.Y.); zhenhao_xu@sdu.edu.cn (Z.X.); \\ Tel.: +86-531-8839-9179 (W.Y.); +86-531-8839-5428 (Z.X.)
}

Received: 28 January 2019; Accepted: 2 April 2019; Published: 15 April 2019

\begin{abstract}
Springs are a source of drinking water and a famous tourist attraction in Jinan, China. In this paper, a multi-index evaluation method was proposed based on a normal cloud model. This model is new graphic model, which could synthetically picture the randomness and fuzziness of concepts. Ten parameters were selected, and water quality was classified into five levels. Three numerical characteristics were calculated, and the weights were assigned by an integrated weighting algorithm. The uncertainty of each spring was calculated by a cloud generator and the integrated certainty grades of water quality were determined. To ensure the accuracy of the normal cloud model, the proposed method was used to assess the water quality of springs in Jinan, China. The results obtained by the proposed method were compared with that of the other four methods. The results obtained by different methods are highly consistent. The proposed cloud model-based method can reflect the water quality level and provides a practical guide for water quality evaluation, as demonstrated in Jinan springs.
\end{abstract}

Keywords: springs; water quality; assessment; normal cloud model; combination weighting

\section{Introduction}

Water plays a significant role in the survival and development of human society [1-7]. Lakes, reservoirs, and rivers provide an important source of drinking water for people. Water quality is largely influenced by natural processes-for example, precipitation rate, weathering processes, and soil erosion, as well as anthropogenic influences, including industrial, urban, and agricultural activities [8-10]. In recent years, the degradation of water quality has been regarded as one of the most serious global ecological issues, especially in developing countries [11]. Therefore, the effective assessment of water quality is critical to ecological sustainability.

Water quality evaluation is a comprehensively multi-index decision-making process. The transformation of qualitative and quantitative concepts needs to be addressed, and the qualitative level should be quantified with different indices. A great deal of methods and methodologies have been proposed to determine water quality in the past few decades, including multivariate statistical models, fuzzy set-based models [12], and hybrid models [13,14]. Multivariate statistical models for randomness have included cluster analysis (CA), factor analysis (FA), and principal component analysis (PCA) [15-17]. The above methods take fuzziness and randomness less into account in the evaluation 
process. A new evaluation method is proposed based on the cloud model theory [18] (, which considers randomness with fuzziness and is effective as a cognitive technology for water quality assessment. The cloud model makes it possible to travel from qualitative concept and quantitative characteristics. This theory has been widely applied to a great number of areas $[19,20]$. For example, in hydrology, Deng et al. [21] proposed a hybrid forecasting method for water quality time series based on a cloud model and fuzzy forecasting. Wang et al. [22] introduced the normal cloud model to evaluate the status of eutrophication.

Related studies have been carried out in lakes, reservoirs, and rivers [20,23,24], but few studies have evaluated the water quality of springs. The spring is an important source of drinking water and one of the most famous tourist attractions in Jinan, China, where springs have attracted tourists from all over the world. In recent years, with the increase in the number of tourists, the water quality of the springs is worsening. There is a need to propose a comprehensive evaluation system to assess the water quality of springs. In the present study, the data of major springs are collected for 10 parameters at 10 different sites in Jinan. It is assumed that the evaluation of spring water quality has ambiguity and randomness. Uncertainties of variables and membership are graphically modeled via probability distributions and the membership function, respectively. A multi-index evaluation system of water quality for springs in Jinan is proposed by using normal cloud model theory.

\section{The Normal Cloud Model}

The cloud model theory is constructed on the idea of fuzzy sets theory [25] and probability concepts [26], proposed by professor $\mathrm{Li}$ [27]. It is a new graphic model, which can synthetically picture the randomness and fuzziness of concepts, and completes the uncertain transformation between qualitative concepts and their quantitative instantiations [28].

Let $X$ be the universe of discourse and $Y$ a qualitative concept connected with $X$. If the quantitative number $x$ belongs to $X$, and $x$ is a random instantiation of the concept $Y$, the certainty grade $\mu(x)$ for $x$ belonging to $Y$ is a random variable which has a stable tendency. The parameter $\mu(x)$ can be estimated as below:

$$
\mu: X \rightarrow[0,1] \quad \forall x \in X \rightarrow \mu(x)
$$

Mathematically, the distribution of $x$, can be determined by three numerical characteristics: expectation parameter $E x$, entropy parameter $E n$ and hyper entropy parameter $\mathrm{He}$ [29-31]. According to Figure 1, Ex is the expectancy of the cloud drop in the universe of discourse and the best characterization of a qualitative concept. En, the entropy of $E x$, reflects the variation range of a cloud drop in the distribution, which is determined by the fuzziness and randomness of the concept. The degree of dispersion of the cloud drops is recognized by $\mathrm{He}$, the entropy of $\mathrm{En}$. In addition, $\mathrm{He}$ can measure the uncertainty of the membership degree and control the aggregation of cloud drops. For example, Figure 1 illustrates a normal cloud model, in which the three numerical characteristics are $E x=50, E n=15$, and $H e=0.01$.

The distribution of $x$ is defined as a cloud, and each $\mathrm{x}$ is called a cloud drop, which is a tool as a quantitative meaning to describe a qualitative concept. The production process of cloud drops represents the uncertainty of conversion between qualitative concept and quantitative values. The certainty grade of a cloud drop reflected the fuzziness and randomness of a concept.

If a number $x \in X$ is a random realization of the concept $Y$ and satisfies $x \sim N\left(E x, E n^{\prime 2}\right)$ and $E n^{\prime} \sim N\left(E n, H e^{2}\right)$, the certainty grade of $x$ belonging to concept $Y$, satisfies

$$
\mu(x)=e^{-\frac{(x-E x)^{2}}{2\left(E n^{\prime}\right)^{2}}}
$$

then the distribution of $x$ on the universal set $X$ is called the one-dimension normal cloud, and each $x$ is defined as a normal cloud drop. 


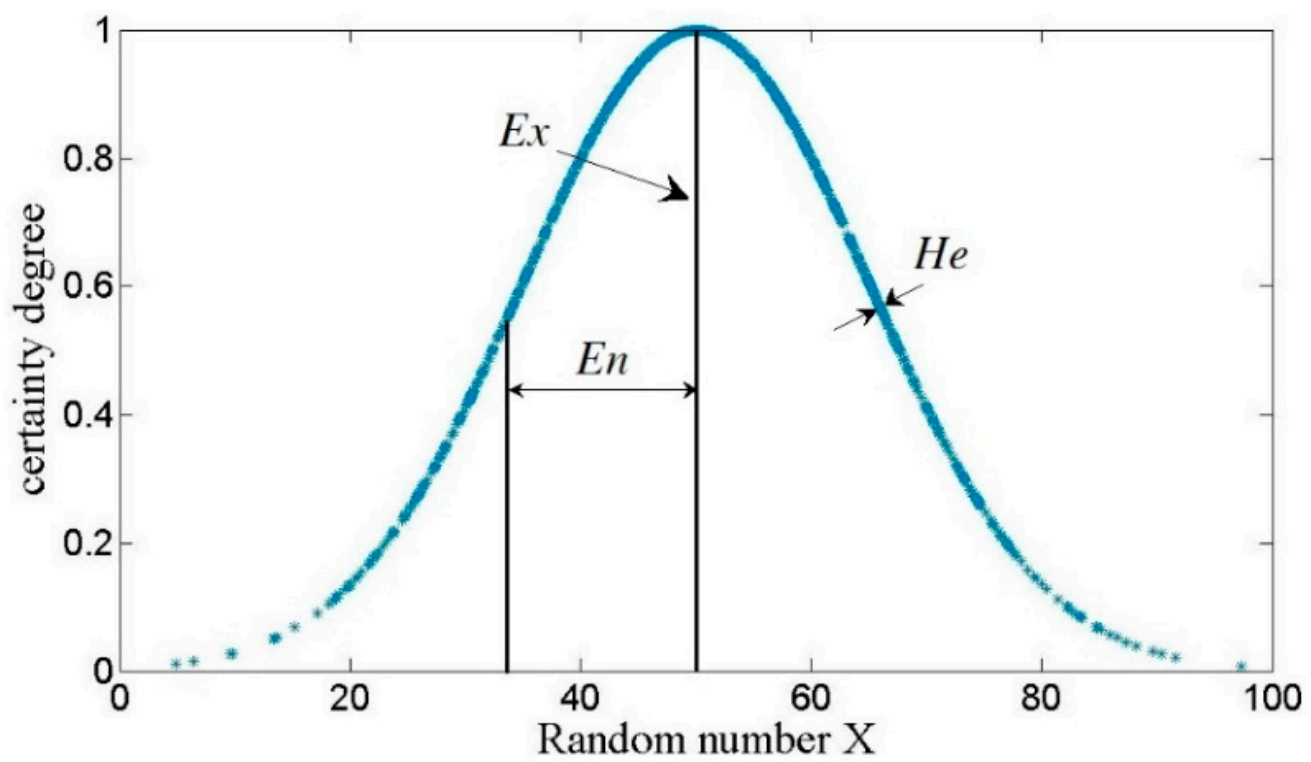

Figure 1. One-dimensional cloud model.

The cloud generator is a cloud generation algorithm that is implemented in software. Cloud generators can achieve the mapping relationship between qualitative concepts and quantitative characteristics, and it is feasible to simulate the human cognition process using cloud generators by computer [32]. There are two common types of generators: the normal cloud generator and the backward cloud generator.

Specifically, the normal cloud generators make it easier to realize the transformation from the qualitative concept to the quantitative characteristic. In contrast, the backward cloud generator can achieve the transformation from quantitative characteristic to qualitative concept. Using generators, as many cloud drops can be produced as are required. The normal cloud generator algorithm can be expressed in the algorithm as follows [20]:

Input: three numerical characteristics of the cloud model $(E x, E n, H e)$ and the required number of cloud drops $n$;

Output: $n$ cloud drops and their certainty degree $\mu\left(x_{i}\right)$.

The algorithm steps can be presented as follows:

(1) Calculate expectation En and the standard deviation $\mathrm{He}$;

(2) Generate a random number $E_{n}^{\prime}: E n^{\prime} \sim N\left(E n, H e^{2}\right)$. The $E_{n}^{\prime}$ is a normally random number of which the expectation is $E n$ and standard deviation is $H e$.

(3) Variable $x_{i}$ is a quantitative value of a qualitative concept-generate a normally random number $x_{i}$ with expectation $E x$ and standard deviation $E_{n}^{\prime}: x_{i} \sim N\left(E x, E n^{2}\right)$;

(4) Calculate certainty degree: $\mu\left(x_{i}\right)=e^{-\frac{\left(x_{i}-E_{x}\right)^{2}}{2\left(E_{n}^{\prime}\right)^{2}}}$;

(5) Generate a cloud drop with the certainty degree $\mu\left(x_{i}\right)$ and the normally random number $x_{i}$;

Repeat steps (1) to (5) until $n$ required cloud drops are generated. 


\section{Study Area}

Jinan is located in Shandong province, China, which is in the north of Mount Tai and south of the Yellow River, at latitude $36^{\circ} 32^{\prime}-36^{\circ} 51^{\prime} \mathrm{N}$, longitude $116^{\circ} 49^{\prime}-117^{\circ} 14^{\prime}$ E. There are more than 600 Springs, and the most famous of these springs are the four big springs: Baotu Springs, Heihu Springs, Pearl Springs, and Wulong Springs. As a result, Jinan is known as the "City of Springs". The formation of springs is closely related to geological and hydrogeological conditions.

The geographical location and the geological conditions of springs in Jinan are shown in Figure 2. Jinan is located at the conjunction of a mountain and a flood plain, which is northwest of Tai mountain and southeast of Lubei plain. Therefore, groundwater flow in this area is from southeast to northwest, which is controlled by geological layers and aquifers. Specifically, the main geological layers in this field are the Cambrian $(\Theta)$, Ordovician $(\mathrm{O})$, Quaternary $(\mathrm{Q})$, Archaean $(\mathrm{Ar})$, and the igneous rock $(\gamma)$ layers. The main active faults are the Dongwu faults, Qianfoshan faults, Licheng faults, and Ganggou faults. Moreover, the springs are recharged by precipitation in the areas, with the Cambrian and Ordovician layers and leakage from the upper Quaternary aquifer. There are many reservoirs and rivers in this area, such as Jinxiuchuan reservoir, Wohushan reservoir, the Yellow River, and the Yufu river, the catchment area of which are up to $7000 \mathrm{~m}^{2}$. Restricted by igneous rocks in the northwest part of the Springs field, groundwater flows upward as soon as the flows approach the north. Later, upward flows finally discharge to the ground, then the famous springs are formed. The Baotu springs, the Heihu springs, the Pearl springs, and Wulong Lake are the most famous springs in Jinan (Figure 3). The area of the Baotu spring, the Pearl spring and the Wulong Lake are about $10,500 \mathrm{~m}^{2}, 1240 \mathrm{~m}^{2}$, $54,000 \mathrm{~m}^{2}$, respectively. However, with the increase of water demand in industry and agriculture, as well as the development of tourism, there is a declining trend in flow rates, and the pollution of springs is becoming more and more serious. To fully understand the pollution situation of springs field in Jinan, a brief assessment of water quality of springs in Jinan is included in this paper.

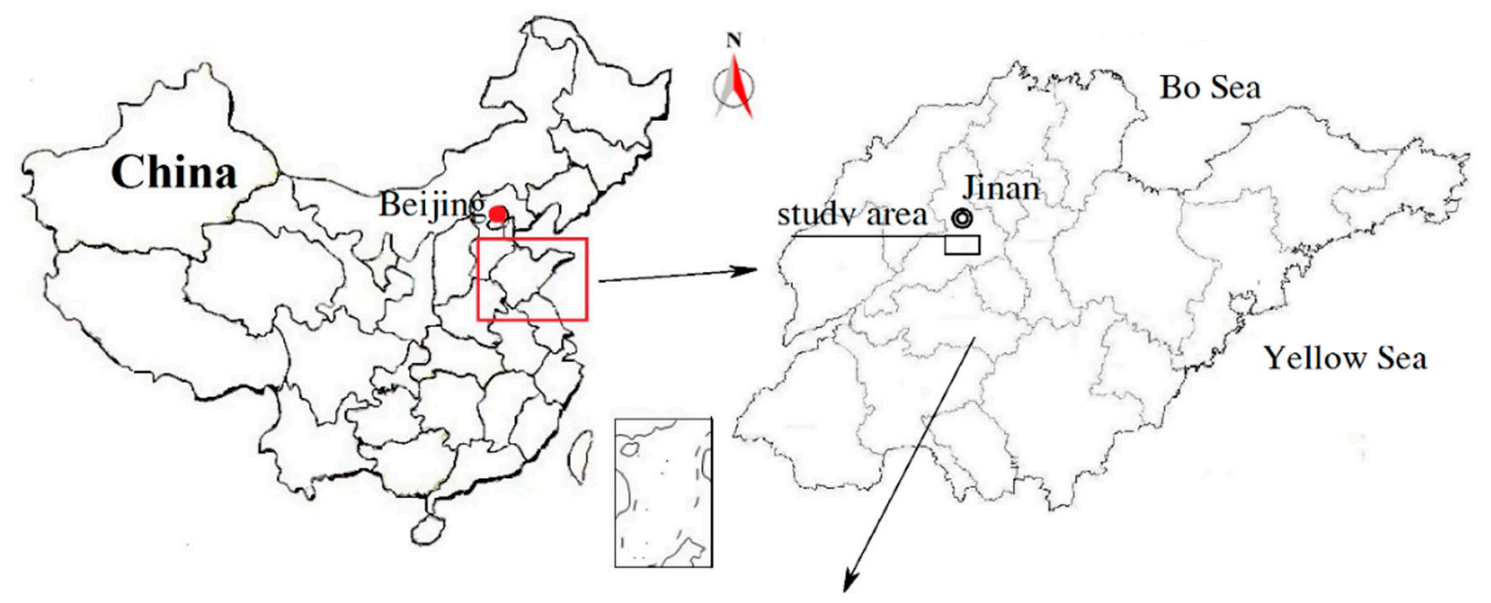

Figure 2. Cont. 

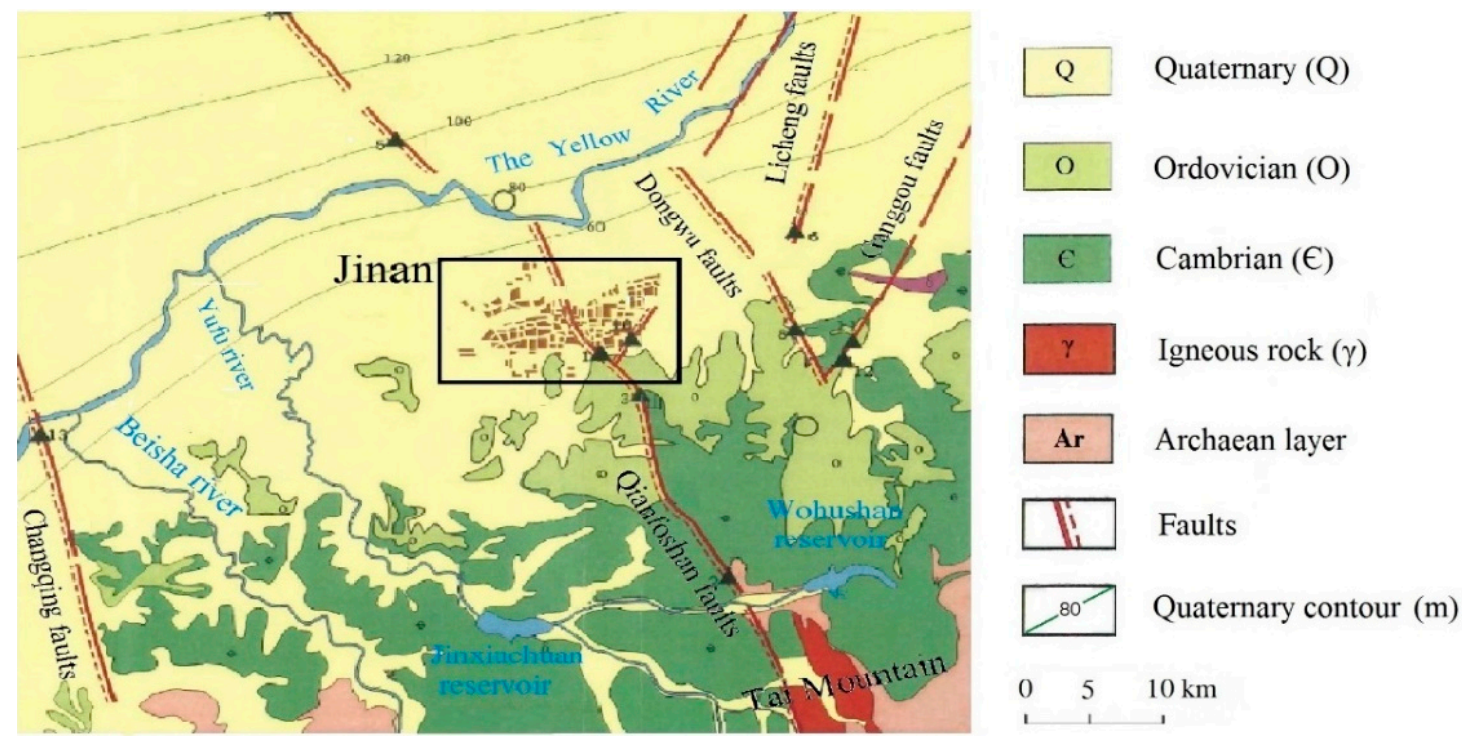

Figure 2. The geographical location and the geological conditions of the springs field in Jinan.

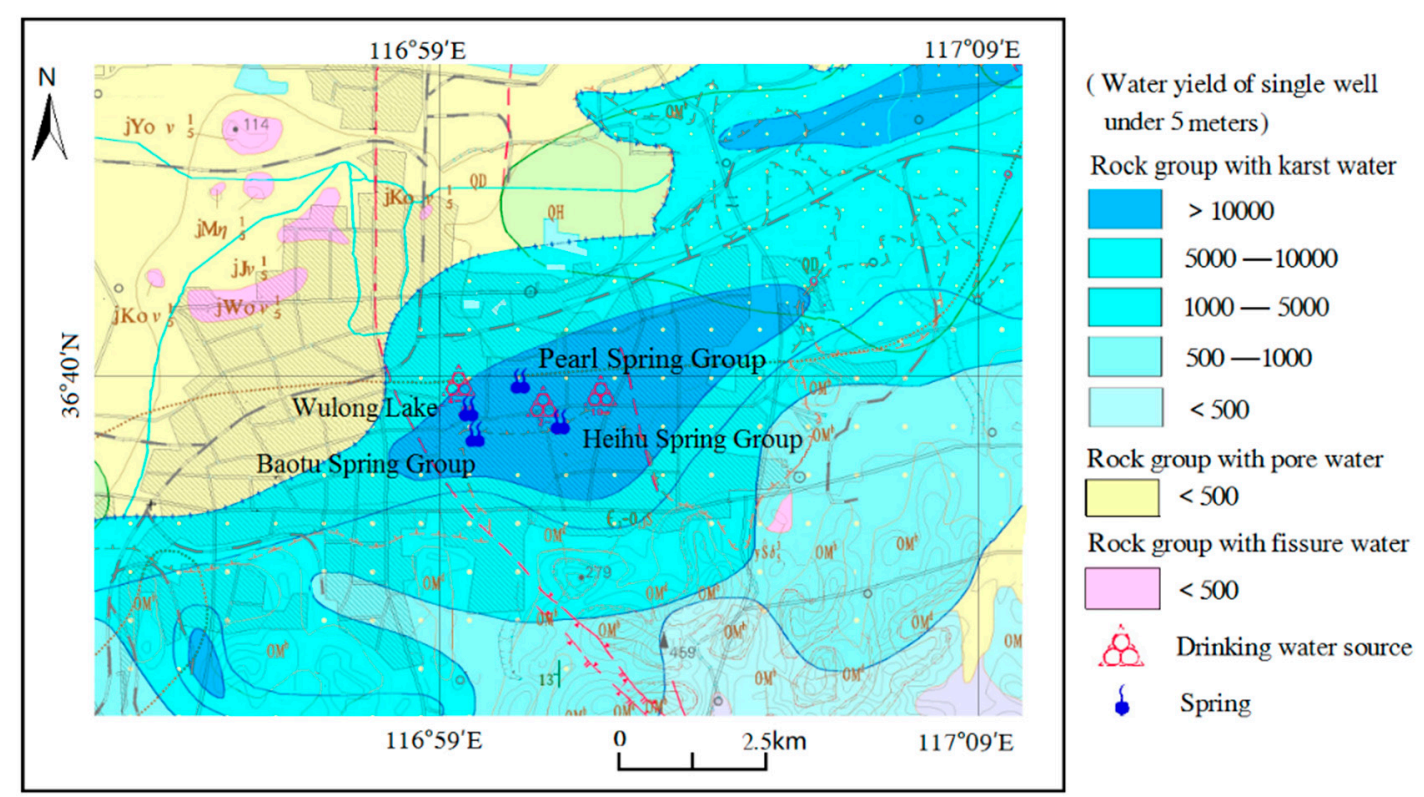

Figure 3. The hydrogeological condition of the springs.

\section{Water Quality Assessment of Springs}

The flow chart of water quality assessment, based on a normal cloud model, is seen in Figure 4 . First, the evaluation criteria of water quality assessment are determined, then we divide them into five levels. Second, based on MATLAB software, three numerical characteristics are calculated, and cloud drops are built in a graphic way. Third, a comprehensive weight calculating algorithm is used to assign weights. Finally, reading the measured data and weights, the certainties of each spring are determined by a normal cloud generator. Then the level of water quality of springs can be determined. 


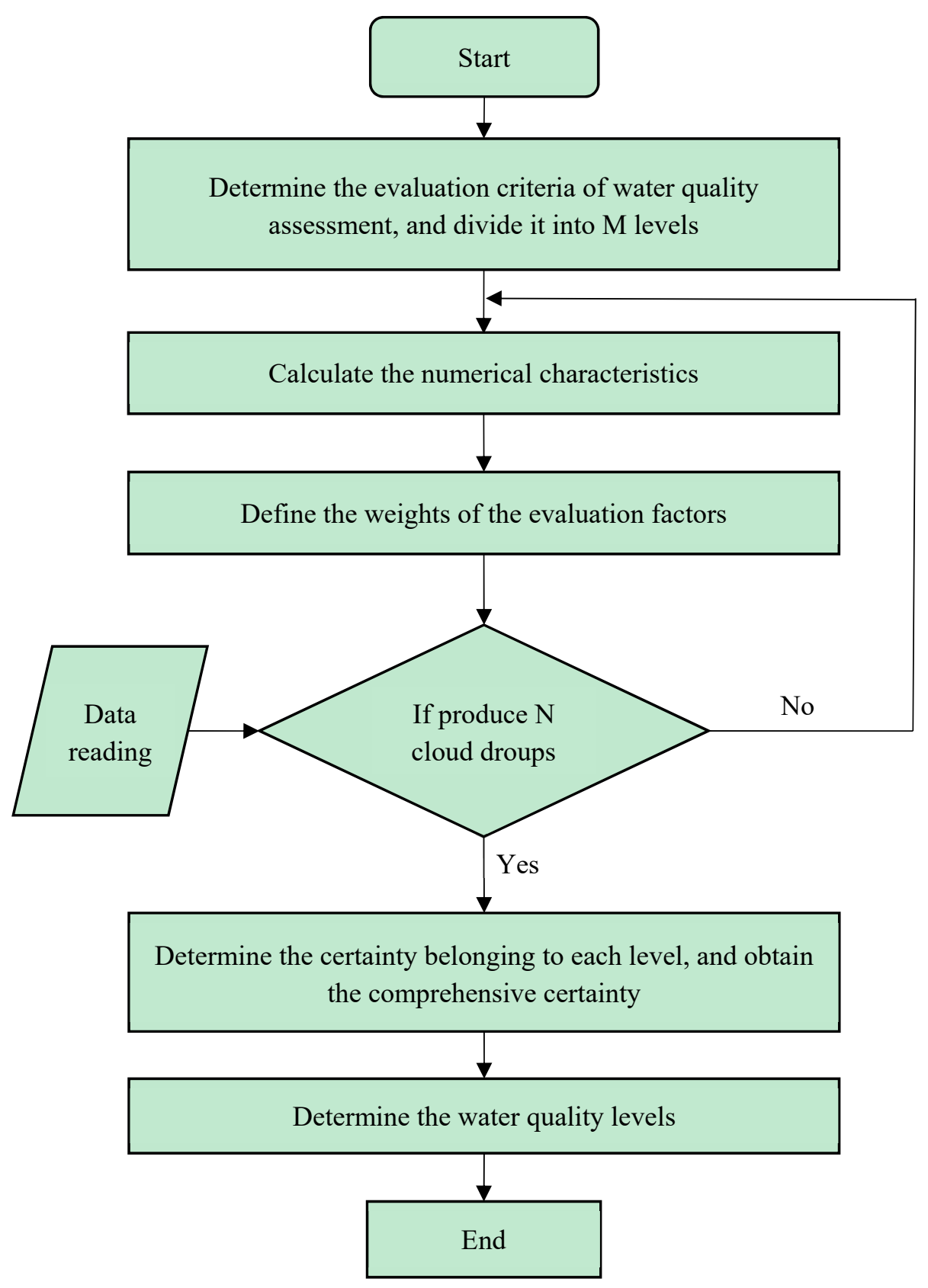

Figure 4. The process of water quality assessment of springs based on a normal cloud model.

\subsection{Assessment Index System}

Water quality is significantly affected by rainfall, human activities, and industrial impacts, as well as soil and geology. Water quality is mainly reflected in physicochemical characteristics, ecotoxicological characteristics, and the quantification of metal concentration [22]. The evaluation criteria are classified into five levels by referring to the Standard of Natural Mineral Water for Drinking [33] and the Hygienic Standard of Water for Drinking [34] in China, as listed in Table 1. Water whose level is I or II is safe for drinking, but water belonging to other levels must be comprehensively purified before drinking and irrigation. 
Table 1. Levels of natural mineral water for drinking in China.

\begin{tabular}{cl}
\hline Level & \multicolumn{1}{c}{ Evaluation } \\
\hline I & The quality of water is very good and it is suitable for direct drinking; this can be \\
the source of many rivers; & The quality of water is good and it generally suitable for direct drinking; \\
III & The quality of water can be drunk after being purified and is suitable for \\
& centralized drinking and irrigation; \\
IV & The quality of water is bad and is suitable for drinking and irrigation after \\
V & The quality of water is unacceptable for drinking or irrigation. \\
\hline
\end{tabular}

To make the results correspond to the practical situation of springs, 10 parameters-total hardness, $\mathrm{Pb}, \mathrm{Cd}$, As, $\mathrm{Hg}$, chloride, fluoride, sulphate, nitrate, and nitrite are adopted as evaluation factors. The evaluation factors and their classification standards are detailed in Table 2.

Table 2. Classification standards of natural mineral water for drinking in China [33,34].

\begin{tabular}{cccccc}
\hline Evaluation Indices & I & II & III & IV & V \\
\hline Total Hardness $(\mathrm{mg} / \mathrm{L})$ & $\leq 150$ & $150 \sim 300$ & $300 \sim 450$ & $450 \sim 550$ & $\geq 550$ \\
$\mathrm{~Pb}(\mathrm{mg} / \mathrm{L})$ & $\leq 0.005$ & $0.005 \sim 0.008$ & $0.008 \sim 0.03$ & $0.03 \sim 0.05$ & $\geq 0.05$ \\
$\mathrm{Cd}(\mathrm{mg} / \mathrm{L})$ & $\leq 0.005$ & $0.005 \sim 0.01$ & $0.01 \sim 0.03$ & $0.03 \sim 0.05$ & $\geq 0.05$ \\
$\mathrm{As}(\mathrm{mg} / \mathrm{L})$ & $\leq 0.0001$ & $0.0001 \sim 0.001$ & $0.001 \sim 0.01$ & $0.01 \sim 0.1$ & $\geq 0.1$ \\
$\mathrm{Hg}(\mathrm{mg} / \mathrm{L})$ & $\leq 0.00005$ & $0.00005 \sim 0.0005$ & $0.0005 \sim 0.0075$ & $0.0075 \sim 0.001$ & $\geq 0.001$ \\
Chloride $(\mathrm{mg} / \mathrm{L})$ & $\leq 50$ & $50 \sim 150$ & $150 \sim 250$ & $250 \sim 350$ & $\geq 350$ \\
Fluoride $(\mathrm{mg} / \mathrm{L})$ & $\leq 1.0$ & $\leq 1.0$ & $\leq 1.0$ & $\leq 2.0$ & $\geq 2.0$ \\
Nitrate $(\mathrm{mg} / \mathrm{L})$ & $\leq 2.0$ & $2.0 \sim 5.0$ & $5.0 \sim 20$ & $20 \sim 30$ & $\geq 30$ \\
Sulphate $(\mathrm{mg} / \mathrm{L})$ & $\leq 50$ & $50 \sim 150$ & $150 \sim 250$ & $250 \sim 350$ & $\geq 350$ \\
Nitrite $(\mathrm{mg} / \mathrm{L})$ & $\leq 0.001$ & $0.001 \sim 0.01$ & $0.01 \sim 0.02$ & $0.02 \sim 0.1$ & $\geq 0.1$ \\
\hline
\end{tabular}

\subsection{Numerical Characteristics}

Three numerical characteristics of the normal cloud model were determined according to the specific evaluation criteria (Table 2) [19,22].

For a bilateral boundary of the form $\left[B_{i \min }, B_{i \max }\right]$, three numerical characteristics $(E x, E n, H e)$ can be determined as suggested in Equations (3)-(5):

$$
\begin{gathered}
E x_{i}=\frac{B_{i \max }+B_{i \min }}{2} \\
E n_{i}=\frac{E x_{i+1}-E x_{i}}{3} \\
H e=k
\end{gathered}
$$

Apart from that, if a variable has only a single boundary, like $\left[-\infty, B_{\text {imin }}\right]$ or $\left[B_{\text {imax }},+\infty\right]$, its default boundary parameter and $E x_{i}$ can be determined by the value of the upper and lower bounds:

$$
\begin{gathered}
E x_{i}=1.5 B_{i \min } \\
E n_{i}=\frac{E x_{i}}{3}
\end{gathered}
$$

In detail, $B_{i \min }$ and $B_{i \max }$ are the minimum and maximum values that can be accepted by a qualitative concept. For instance, for level III of total hardness, $B_{i \min }=300$ and $B_{i \max }=450$, so the corresponding numerical characteristics can be calculated as $E x=375$ and $E n=50$. Moreover, He is a constant $(k<0.5)$, which controls the granularity of a cloud drop, and $\mathrm{He}$ can be adjusted appropriately according to the practical situation. In the present study, $k$ is assumed as 0.1 to balance the variation and 
robustness of water quality assessment. In that situation, the cloud parameters would be calculated by Equation (2), and all parameters are determined as in Table 3.

Table 3. Numerical characteristic parameters of the cloud model.

\begin{tabular}{|c|c|c|c|c|c|c|c|c|c|c|}
\hline \multirow{2}{*}{ Levels } & \multicolumn{2}{|c|}{ Total Hardness } & \multicolumn{2}{|c|}{$\mathbf{P b}$} & \multicolumn{2}{|c|}{ Nitrate } & \multicolumn{2}{|c|}{ Hg } & \multicolumn{2}{|c|}{$\mathrm{Cd}$} \\
\hline & $E n$ & $E x$ & $E n$ & $E x$ & $E n$ & $E x$ & $E n$ & $E x$ & $E n$ & $E x$ \\
\hline I & 75 & 50 & 0.0025 & 0.0013 & 0.0025 & 0.0017 & 0.000025 & 0.000083 & 0.00005 & 0.000167 \\
\hline II & 225 & 50 & 0.0065 & 0.0042 & 0.0065 & 0.0042 & 0.000275 & 0.000097 & 0.00055 & 0.00165 \\
\hline III & 375 & 41.7 & 0.019 & 0.007 & 0.019 & 0.0067 & 0.000625 & 0.000113 & 0.0055 & 0.0165 \\
\hline IV & 500 & 108.3 & 0.04 & 0.0116 & 0.04 & 0.0117 & 0.000875 & 0.00021 & 0.055 & 0.0317 \\
\hline $\mathrm{V}$ & 825 & 275 & 0.075 & 0.025 & 0.075 & 0.025 & 0.0015 & 0.0005 & 0.15 & 0.05 \\
\hline \multirow{2}{*}{ Levels } & \multicolumn{2}{|c|}{ Chloride } & \multicolumn{2}{|c|}{ Fluoride } & \multicolumn{2}{|c|}{ Nitrate } & \multicolumn{2}{|c|}{ Sulphate } & \multicolumn{2}{|c|}{ Nitrite } \\
\hline & $E n$ & $E x$ & $E n$ & $E x$ & $E n$ & $E x$ & $E n$ & $E x$ & $E n$ & $E x$ \\
\hline I & 25 & 25 & 0.5 & 0.167 & 1 & 0.83 & 25 & 25 & 0.0005 & 0.00167 \\
\hline II & 100 & 33 & 1 & 0 & 3.5 & 3 & 100 & 33 & 0.0055 & 0.00317 \\
\hline III & 200 & 33 & 1 & 0 & 12.5 & 4.16 & 200 & 33 & 0.015 & 0.015 \\
\hline IV & 300 & 75 & 1 & 0.167 & 25 & 6.67 & 300 & 75 & 0.06 & 0.03 \\
\hline $\mathrm{V}$ & 525 & 175 & 1.5 & 0.5 & 45 & 15 & 525 & 175 & 0.15 & 0.05 \\
\hline
\end{tabular}

\subsection{Assessment Index Weight}

Considering that the weight of each index is not absolute but relative, a comprehensive weight calculating algorithm is introduced to determine weights of indices. In particular, the analytic hierarchy process method (AHP) [35] can fully draw on the experience of experts, and it has been widely used to weight factors based on multiple criteria. Therefore, this paper employed the AHP method for the subjective weight calculation. The projection pursuit classifications (PP) [36-38] are adopted to calculate the objective weight, to reduce human factors and balance the subjective uncertainty and randomness of AHP. The PP method is a statistical method for analyzing and dealing with high-dimensional data. It can project high-dimensional data to low-dimensional subspaces, and the characteristics of structure of high-dimensional data can be studied based on analyzing the scattered structure of low-dimensional projected data. Furthermore, the relevancy between evaluation factors and water quality could be determined quantitatively by the comprehensive weight calculating algorithm. The proposed algorithm is a practical method, which could reconcile subjectivity and objectivity in the weight calculating.

The basic calculating steps are as follows.

To calculate the subjective weight by the AHP approach, a hierarchy structure model is constructed on the basis of an assessment index system, and is then scored by experts. Next is setting up a judgement matrix, ranking evaluation indices of water quality and completing the consistency checking, and calculating the total weights $w_{i}$ [39]. Finally, the relative importance of 10 indices is identified from high to low as $\mathrm{Hg}$, As, Cd, Pb, Sulphate, Nitrate, Chloride, Fluoride, Nitrite, and Total Hardness (Table 4). The analytic hierarchy process is used to calculate the subjective weight as the relative importance of the indicator, and thus the sum of the subjective weights may not be 1 .

To calculate the objective weight, in view of the different evaluation units, the normalization method is used to make indices dimensionless. After normalization, the variation tendency of the primitive value is maintained. The indices are normalized using Equation (8):

$$
x_{i j}=\frac{x_{i j}^{0}}{x_{j \max }^{0}}
$$

In the formula, $x_{i j}$ is the $i$ index of the $j$ samples for the water quality, $i=1,2, \ldots, n ; j=1,2, \ldots, m$. 
Table 4. Weights of evaluation indices for water quality assessment.

\begin{tabular}{ccccccccccc}
\hline $\begin{array}{c}\text { Evaluation } \\
\text { Indices }\end{array}$ & $\begin{array}{c}\text { Total } \\
\text { Hardness }\end{array}$ & $\mathbf{P b}$ & $\mathbf{C d}$ & $\mathbf{A s}$ & $\mathbf{H g}$ & Chloride & Fluoride & Nitrate & Sulphate & Nitrite \\
\hline $\begin{array}{c}\text { AHP-based } \\
\text { weight } \\
\begin{array}{c}\text { PP-based } \\
\text { weight }\end{array}\end{array}$ & 0.108 & 0.245 & 0.258 & 0.306 & 0.360 & 0.173 & 0.165 & 0.183 & 0.195 & 0.113 \\
$\begin{array}{c}\text { AHP-PP } \\
\text { weight }\end{array}$ & 0.096 & 0.075 & 0.121 & 0.113 & 0.128 & 0.105 & 0.082 & 0.094 & 0.108 & 0.078 \\
\hline
\end{tabular}

In this table, AHP is the analytic hierarchy process method and PP is the projection pursuit classifications.

Data were projected from high-dimension to low-dimension by linear projection. Let $a_{j}$ be the $m$ dimensional unit direction vector-then one-dimensional projection eigenvalue $z_{i}(i=1,2, \ldots, n)$ can be calculated by Equation (9):

$$
z_{i}=\sum_{j=1}^{m} a_{j} x_{i j}
$$

After that, the objective function should be constructed as

$$
\begin{gathered}
Q\left(a_{j}\right)=S_{z} D_{z} \\
S_{z}=\sqrt{\sum_{i=1}^{n}\left(z_{i}-E(z)\right)^{2} /(n-1)} \\
D_{z}=\sum_{i=1}^{n} \sum_{j=1}^{m}(R-r(i, j)) u(R-(i, j))
\end{gathered}
$$

In the formulas, $S_{z}$ is the standard deviation of the projection eigenvalue, which reflects the distances between different classes. $D_{z}$ is the local density of the projection value. $E(z)$ is the mean value of $\left\{z_{i} \mid i=1,2, \cdots, n\right\} ; R$ is the local density radius, and $k$ is assumed as $m ; r(i, j)$ is the distance between $z_{i}$ and $z_{j}$; and $r(i, j)=\left|Z_{i}-Z_{j}\right| ; u(R-r(i, j))$ is a unit speed function, which can be calculated as

$$
u(R-(i, j))= \begin{cases}1 & R \geq r(i, j) \\ 0 & R>r(i, j)\end{cases}
$$

When Equation (10) achieve the maximum value, the projection direction can best reflect the data characteristics:

$$
\max Q\left(a_{j}\right)=S_{z} D_{z}
$$

To solve this nonlinear optimization problem, a real-coded accelerating genetic algorithm (RAGA) was used. Considering $\sum_{i=1}^{n} a_{j} \neq 1$ and $\sum_{i=1}^{n} a_{j}^{2}=1$, the final weight $v_{i}$ of each level was determined with the mean of $a_{i}^{2}$ :

$$
v_{i}=\left\{a_{1}^{2}, a_{2}^{2}, \cdots a_{n}^{2}\right\}
$$

According to the principle of minimum entropy [40], the hybrid AHP-PP weights are given as the formula below:

$$
c_{i}=\frac{\sqrt{w_{i} v_{i}}}{\sum_{j=1}^{n} \sqrt{w_{i} v_{i}}}
$$

\subsection{Generation of Normal Cloud Model}

The normal cloud model of water quality of springs can be set up by the normal cloud generator. The certainty grade of each level of water quality assessment is calculated by the normal cloud generator. 
Then, combining with the hybrid AHP-PP weights, the integrated certainty degree $M$ can be calculated as the following:

$$
M=\sum_{\mathrm{i}=1}^{j} \mu c_{i}
$$

In the formula, $\mu$ is the certainty grade of an assessment level, and $c_{i}$ is the weight of index $i$.

\section{Results and Discussion}

Water quality assessment of springs in Jinan is of great uncertainty, and randomness and fuzziness are the two most important uncertainties. In other words, accurate intensions and exact boundaries of the extensions are hard obtain in the evaluation process. It is essential to introduce the cloud model to discuss the randomness and fuzziness in water quality assessment.

In the present study, ten springs in Jinan were chosen as the study area. Some engineers and scientists were employed by the environmental protection department of Jinan to collect water quality data. The water quality data collected by the environmental protection department of Jinan are given in Table 5 [41,42].

Table 5. Measured values of evaluation indices of springs in Jinan.

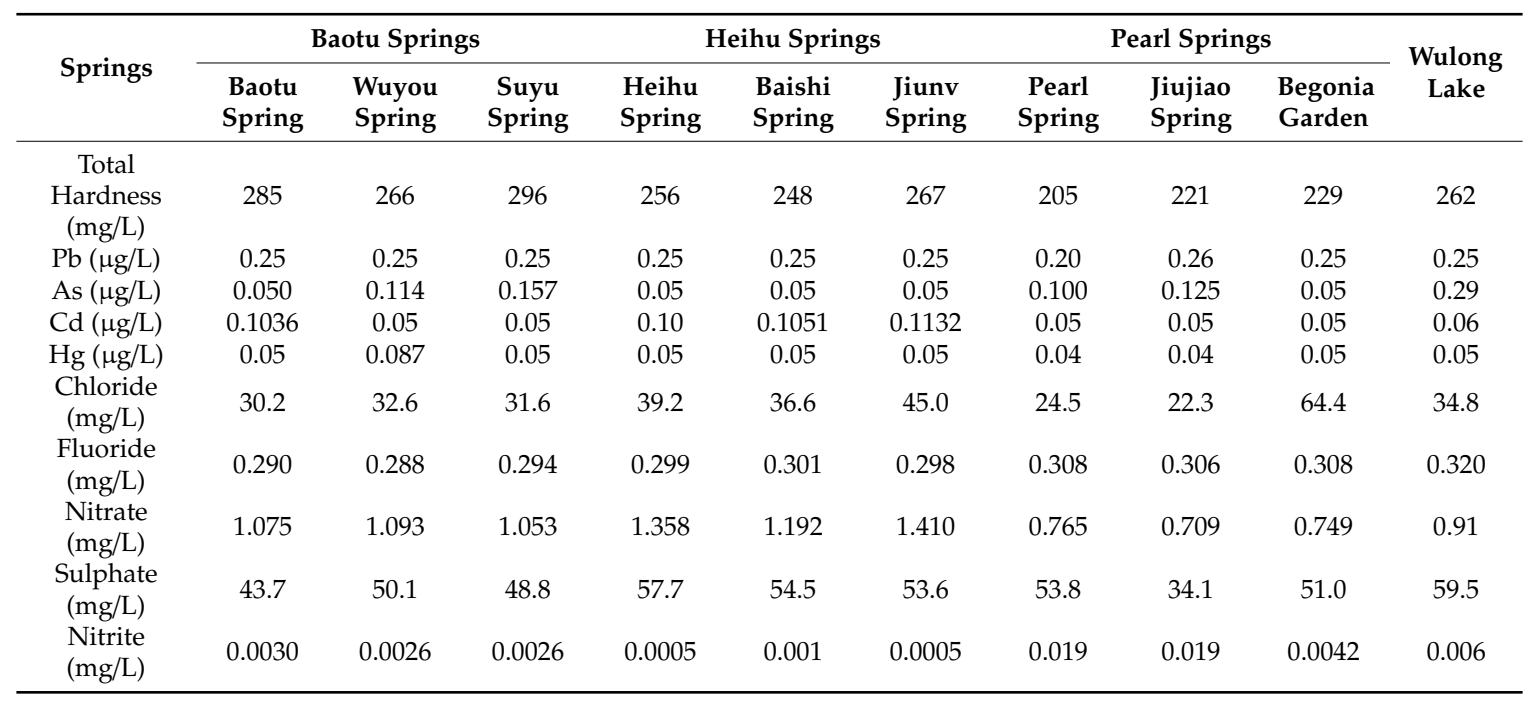

After completing the weight calculation, the distributions of certainty degrees of five grades are calculated and illustrated in Figure 5. In Figure 5, the abscissa represents the actual value of evaluation index, and the ordinate represents the certainty grade. Therefore, the more the cloud drops, the better the evaluation effect. 

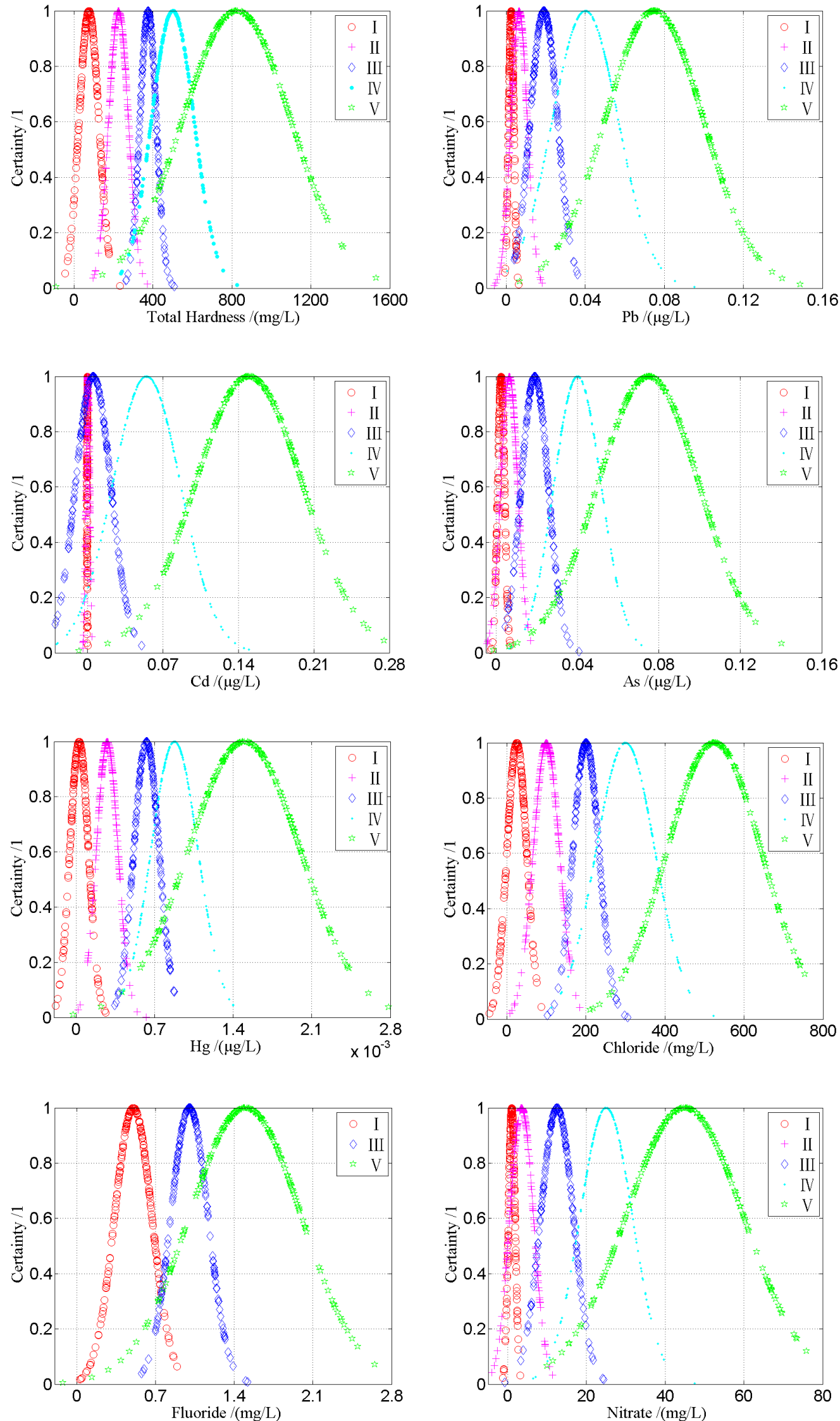

Figure 5. Cont. 

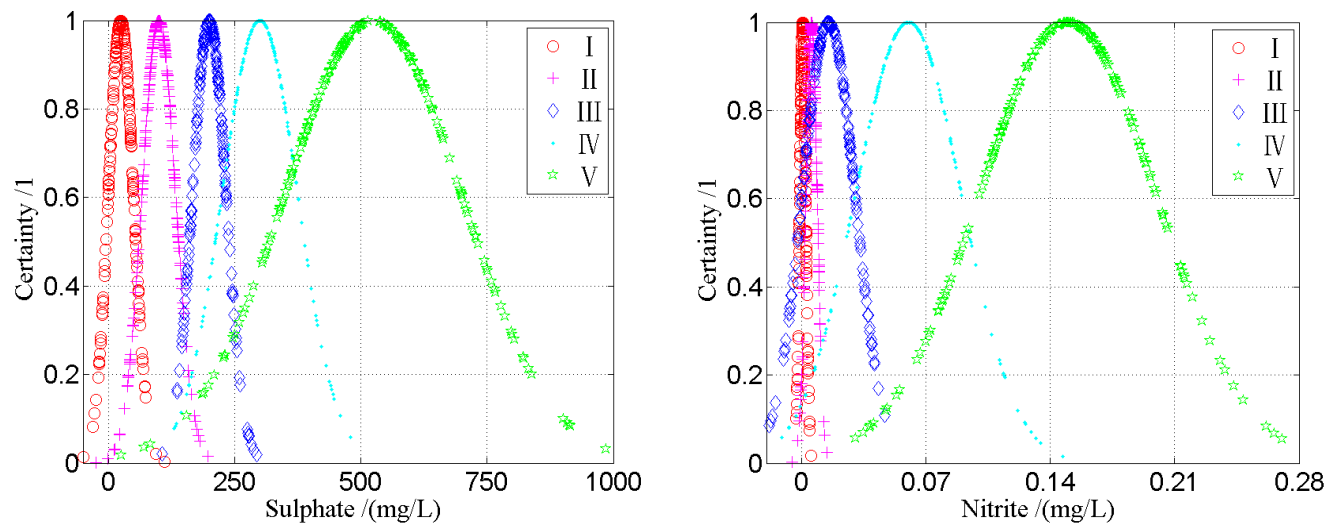

Figure 5. Cloud for each evaluation factor, established by the normal cloud generator.

Based on the cloud model method, the process can be carried out as follows:

(1) First, we determined the evaluation criteria of water quality assessment, and divided it into five levels. Then the numerical characteristics can be calculated by Equations (3)-(7).

(2) In view of the comprehensive weight calculating algorithm, the weights of indices are given in Table 4.

(3) Based on the obtained normal cloud model method and the weights, the certainty degree can be discerned by the normal cloud generator.

(4) The final evaluation results of ten springs are presented in Table 6.

Table 6. The final evaluation results of the springs.

\begin{tabular}{ccccccc}
\hline \multirow{2}{*}{ Spring } & \multicolumn{5}{c}{ Final Certainty Degrees } & \multirow{2}{*}{$\begin{array}{c}\text { The Normal Cloud } \\
\text { Model Method }\end{array}$} \\
\cline { 2 - 5 } & $\boldsymbol{M ( I )}$ & $\boldsymbol{M}(\mathrm{II})$ & $\boldsymbol{M ( I I I )}$ & $\boldsymbol{M ( I V )}$ & $\boldsymbol{M ( V )}$ & $\mathrm{I}$ \\
Baotu Spring & 0.8632 & 0.5846 & 0.4859 & 0.1454 & 0.0209 & $\mathrm{II}$ \\
Wuyou Spring & 0.7681 & 0.7844 & 0.3561 & 0.0755 & 0.0058 & $\mathrm{II}$ \\
Suyu Spring & 0.7578 & 0.7605 & 0.4365 & 0.1182 & 0.0176 & $\mathrm{I}$ \\
Heihu Spring & 0.7747 & 0.5826 & 0.3998 & 0.2003 & 0.0319 & $\mathrm{I}$ \\
Baishi Spring & 0.8425 & 0.5561 & 0.3469 & 0.1584 & 0.0121 & $\mathrm{I}$ \\
Jiunv Spring & 0.7485 & 0.7343 & 0.4523 & 0.1968 & 0.0255 & $\mathrm{I}$ \\
Pearl Spring & 0.9266 & 0.4895 & 0.2563 & 0.1024 & 0.0089 & $\mathrm{I}$ \\
Jiujiao Spring & 0.8975 & 0.4938 & 0.2158 & 0.1115 & 0.0052 & $\mathrm{I}$ \\
Begonia Garden & 0.8817 & 0.5194 & 0.3240 & 0.1509 & 0.0264 & $\mathrm{I}$ \\
Wulong Lake & 0.8427 & 0.6632 & 0.2971 & 0.1143 & 0.0366 & \\
\hline
\end{tabular}

The reliability of the normal cloud model-based method was assessed by comparison with the single factor index (SFI) method [43], the Nemerow index (NI) method [44], the variable fuzzy sets (VFS) method [24], and the artificial neural networks (ANN) method. The results of these methods are compared in Table 7.

In the SFI method, the measured data of a spring are compared with water quality standards; then, the highest pollution grade of water quality was selected as the grade of this spring. In the NI method, water quality is assessed by calculation of comprehensive pollution index. In the variable fuzzy sets model, a comprehensive evaluation vector is established by performing an operation between the set of fuzzy weights and the fuzzy relationship matrix. Lastly, an artificial neural network is established with three layers in the ANN model, which represent independent and dependent variables of the system, respectively. Specifically, the input layer has ten neurons and the output layer has five neurons in the present study.

In Table 6, each spring can be generally classified by five levels from low to high. The final levels of Baotu Spring, Heihu Spring, Baishi Spring, Jiunv Spring, Pearl Spring, Jiujiao Spring, Begonia Garden, 
and Wulong Lake are I; most of Wuyou Spring and Suyu Spring are level II. It can be concluded from Table 7 that the calculated results obtained by various methods are basically the same, particularly for Wuyou Spring, whose final grade is II. The 90\% (9/10) final levels are the same as those of the variable fuzzy sets method and the artificial neural networks method, and the $80 \%(8 / 10)$ results are exactly same as those of the Nemerow index method. The $20 \%(2 / 10)$ results are exactly same as those of the single factor index method. The data in Table 6 show high consistency of the results between the proposed normal cloud model and other four methods, considering that the SFI method puts emphasis on the most polluting indicator, which is one-sided. In brief, the normal cloud method is highly representative in these methods.

Table 7. Comparison of water quality levels by various methods.

\begin{tabular}{cccccc}
\hline Spring & $\begin{array}{c}\text { Normal Cloud } \\
\text { Model Method }\end{array}$ & $\begin{array}{c}\text { Single Factor } \\
\text { Index Method }\end{array}$ & $\begin{array}{c}\text { Nemerow } \\
\text { Index Method }\end{array}$ & $\begin{array}{c}\text { Variable Fuzzy } \\
\text { Sets Method }\end{array}$ & $\begin{array}{c}\text { Artificial Neural } \\
\text { Networks Method }\end{array}$ \\
\hline Baotu Spring & I & II & I & I & I \\
Wuyou Spring & II & II & II & II & II \\
Suyu Spring & II & II & II & II & I \\
Heihu Spring & I & II & II & I & I \\
Baishi Spring & I & II & I & I & I \\
Jiunv Spring & I & II & I & I & I \\
Pearl Spring & I & II & I & I & II \\
Jiujiao Spring & I & II & II & I & I \\
Begonia Garden & I & II & I & I & I \\
Wulong Lake & I & II & I & & \\
\hline
\end{tabular}

It is worth noting that the cloud model not only achieves transformation between qualitative concepts and quantitative characteristics, but also provides more details about the water quality levels. For example, the total hardness of Baotu Spring was $285 \mathrm{mg} / \mathrm{L}$, which should belong to grade II according to Table 2. In addition, the certainty degrees of total hardness obtained by the normal cloud generator are $\mu_{I}=0.0052, \mu_{I I}=0.4867, \mu_{I I I}=0.1574, \mu_{I V}=0.0093$ and $\mu_{V}=0.0004$. Therefore, the certainty degree by quantitative analysis is $\mu_{I I}>\mu_{I I I}>\mu_{I V}>\mu_{I}>\mu_{V}$, and the total hardness of Baotu Spring more likely belongs to grade II, likely belongs to grade III, and almost impossibly belongs to grades I, IV, and V. The conclusion is consistent with qualitative analysis. Furthermore, the level of Pearl Spring is more likely to be I than that of Jiunv Spring and Jiujiao Spring, because the certainty degree for level I of Pearl Spring (0.9266) is higher than that of Jiunv Spring (0.7485) and Jiujiao Spring (0.8975). In other words, the results based on the normal cloud model not only reflect the water quality level accurately, but also further judge the pollution degree of water quality for different springs on the same level.

Among all the springs in Jinan, Baotu Springs are the most visited. Baotu Spring, Wuyou Spring, and Suyu Spring hosted an average of more than 20,000 visitors a day in the tourist season, up to a maximum of 50,000 during the Spring Festival and Lantern Festival. Moreover, there are some new toilets and a new subway being built near the Wuyou Spring and the Suyu Spring. The most likely causes of pollution for these springs are anthropogenic contamination and the recharge of groundwater during the construction of subways. Therefore, the evaluation results of the proposed method are basically consistent with the actual situation. In general, the water quality levels of springs in Jinan are mostly grade I, which is suitable for drinking.

\section{Conclusions}

A multi-index evaluation system is proposed to assess the water quality of springs based on normal cloud theory in the present study. Required cloud drops were generated based on three numerical characteristics calculated by cloud generator algorithm. The weights of indices are rationally assigned by a comprehensive weight calculating algorithm, which could reconcile subjectivity and 
objectivity in the weight calculating. Finally, the certainty of each spring belonging to each level can be calculated by a cloud generator, and the levels of water quality of springs are determined.

The present method is applied to the water quality assessment of springs in Jinan. The results are compared with those from other four methods: the SFI method, the NI method, the VFS method and the ANN method. The final levels of Baotu Spring, Heihu Spring, Baishi Spring, Jiunv Spring, Pearl Spring, Jiujiao Spring, Begonia Garden, and Wulong Lake are all level I. The final levels of Wuyou Spring and Suyu Spring are level II. The calculated results obtained by various methods are almost the same, particularly for Wuyou Spring. In other words, the results of the proposed normal cloud model are highly consistent with that of the other four methods. Moreover, the present method can not only reflect the water quality level accurately, but also further judge the pollution degree of water quality for different springs by comparing the certainty of the same level.

The normal cloud model provides a practical guide for the water quality evaluation of springs. In the present study, the one-dimensional normal cloud model is introduced into the water assessment of springs. In view of the successful application of the present model, a two-dimensional and a multi-dimensional cloud modeling strategy are worth exploring with regard to water assessment or other further applications.

Author Contributions: Conceptualization, Z.X. and W.Y.; methodology: Z.X. and X.W.; resources: Y.X.; data curation: Y.X.; writing—original draft preparation: X.W. and J.H.; writing-review and editing: X.W.and P.L.; supervision: W.Y.

Funding: We would like to acknowledge the financial support from the National Natural Science Foundation of China (Grant No.s: 51879148, 51879153, 41772298, 51739007, 51309144).

Conflicts of Interest: The authors declare no conflict of interest.

\section{References}

1. Astel, A.; Małek, S.; Makowska, S. Linear discriminant function analysis in assessment of chemical profiles for Black and White Vistula rivers in "Barania Góra" sanctuary forest area (Poland, Silesian Beskid). Water Air Soil Pollut. 2008, 195, 137-149. [CrossRef]

2. Żelazny, M.; Astel, A.; Wolanin, A.; Małek, S. Spatiotemporal dynamics of spring and stream water chemistry in a high-mountain area. Environ. Pollut. 2011, 159, 1048-1057. [CrossRef]

3. Valentukevičienè, M.; Bagdžiūnaitè-Litvinaitienè, L.; Chadyšas, V.; Litvinaitis, A. Evaluating the Impacts of Integrated Pollution on Water Quality of the Trans-Boundary Neris (Viliya) River. Sustainability 2018, 10, 4239. [CrossRef]

4. Möhlenkamp, P.; Beebe, C.K.; McManus, M.A.; Kawelo, A.H.; Kotubetey, K.; Lopez-Guzman, M.; Nelson, C.E.; Alegado, R. Cultural Restoration Improves Water Budget and Water Quality Dynamics in He'eia Fishpond. Sustainability 2019, 11, 161. [CrossRef]

5. Li, S.C.; Xu, Z.H.; Huang, X.; Lin, P.; Zhao, X.C.; Zhang, Q.S.; Yang, L.; Zhang, X.; Sun, H.F.; Pan, D.D. Classification, geological identification, hazard mode and typical case studies of hazard-causing structures for water and mud inrush in tunnels. Chin. J. Rock Mech. Eng. 2018, 37, 1041-1069. [CrossRef]

6. Wang, X.T.; Li, S.C.; Xu, Z.H.; Lin, P.; Hu, J.; Wang, W.Y. Analysis of Factors Influencing Floor Water Inrush in Coal Mines: A Nonlinear Fuzzy Interval Assessment Method. Mine Water Environ. 2019, 38, 81-92. [CrossRef]

7. Xu, Z.H.; Wang, X.T.; Li, S.C.; Gao, B.; Shi, S.S.; Xu, X.J. Parameter Optimization for the Thickness and Hydraulic Conductivity of Tunnel Lining and Grouting Rings. KSCE J. Civ. Eng. 2019. [CrossRef]

8. Astel, A.; Małek, S.; Krakowian, K. Multivariate exploration and classification applied to the chemical composition of spring waters in sanctuary forest areas. Int. J. Environ. Anal. Chem. 2009, 89, 597-620. [CrossRef]

9. Kosmowska, A.; Żelazny, M.; Małek, S.; Siwek, J.P.; Jelonkiewicz, . Effect of deforestation on stream water chemistry in the Skrzyczne massif (The Beskid Śląski Mountaion in souther Poland). Sci. Total Environ. 2016, 568, 1044-1053. [CrossRef] [PubMed] 
10. Jasik, M.; Małek, S.; Żelazny, M. Effect of water stage and tree stand composition on spatiotemporal differentiation of spring water chemistry draining Carpathian flysch slopes (Gorce Mts). Sci. Total Environ. 2017, 599-600, 1630-1637. [CrossRef]

11. Kalin, L.; Isik, S.; Schoonover, J.E.; Lockaby, B.G. Predicting water quality in unmonitored watersheds using artificial neural networks. J. Environ. Qual. 2010, 39, 1429-1440. [CrossRef] [PubMed]

12. Wang, Z.C.; Qiao, L.P.; Li, S.; Bi, L. Risk assessment for stability and containment property of an underground oil storage facility in construction phase using fuzzy comprehensive evaluation method. ASCE-ASME 2016, 2. [CrossRef]

13. Liu, L.; Zhou, J.; An, X.; Zhang, Y.; Yang, L. Using fuzzy theory and information entropy for water quality assessment in Three Gorges region, China. Expert Syst. Appl. 2010, 37, 2517-2521. [CrossRef]

14. Sheela, A.M.; Letha, J.; Joseph, S.; Chacko, M.; Thomas, J. Water quality assessment of a tropical coastal lake system using multivariate cluster, principal component and factor analysis. Lakes Reserv. Res. Manag. 2012, 17, 143-159. [CrossRef]

15. Bhardwaj, V.; Singh, D.S.; Singh, A.K. Water quality of the Chhoti Gandak River using principal component analysis, Ganga Plain, India. J. Earth Syst. Sci. 2010, 119, 117-127. [CrossRef]

16. Kamble, S.R.; Vijay, R. Assessment of water quality using cluster analysis in coastal region of Mumbai, India. Environ. Monit. Assess. 2011, 178, 321-332. [CrossRef] [PubMed]

17. Baborowski, M.; Büttner, O.; Einax, J.W. Assessment of water quality in the Elbe River at low water conditions based on factor analysis. CLEAN Soil Air Water 2011, 39, 437-443. [CrossRef]

18. Wang, G.; Xu, C.; Li, D. Generic normal cloud model. Inf. Sci. 2014, 280, 1-15. [CrossRef]

19. Liu, D.; Wang, D.; Wu, J.; Wang, Y.; Wang, L.; Zou, X.; Chen, X. A risk assessment method based on RBF artificial neural network-cloud model for urban water hazard. J. Intell. Fuzzy Syst. 2014, 27, 2409-2416.

20. Wang, D.; Zeng, D.; Singh, V.P.; Xu, P.; Liu, D.; Wang, Y.; Wang, L. A multi-dimension cloud model-based approach for water quality assessment. Environ. Res. 2016, 149, 113-121. [CrossRef]

21. De Melo Gurgel, P.; Navoni, J.A.; De Morais Ferreira, D.; Do Amaral, V.S. Ecotoxicological water assessment of an estuarine river from the Brazilian Northeast, potentially affected by industrial wastewater discharge. Sci. Total Environ. 2016, 572, 324-332. [CrossRef]

22. Wang, D.; Liu, D.; Ding, H.; Singh, V.P.; Wang, Y.; Zeng, X.; Wang, L. A cloud model-based approach for water quality assessment. Environ. Res. 2016, 148, 24-35. [CrossRef]

23. Dudeja, D.; Bartarya, S.K.; Khanna, P.P. Ionic sources and water quality assessment around a reservoir in Tehri, Uttarakhand, Garhwal Himalaya. Environ. Earth Sci. 2013, 69, 2513-2527. [CrossRef]

24. Wang, W.C.; Xu, D.M.; Chau, K.W.; Lei, G.J. Assessment of river water quality based on theory of variable fuzzy sets and fuzzy binary comparison method. Water Resour. Manag. 2014, 28, 4183-4200. [CrossRef]

25. Zadeh, L.A. Fuzzy sets. Inf. Control 1965, 8, 338-353. [CrossRef]

26. Frangopol, D.M. Probability concepts in engineering: Emphasis on applications to civil and environmental engineering. Struct. Infrastruct. Eng. 2008, 4, 413-414. [CrossRef]

27. Li, Z.; Liu, Y. Single rule reasoning mapping for the two dimensional normal cloud model. CAAI Trans. Intell. Syst. 2010, 5, 464-470.

28. Zhang, X.; Liu, Z.; Jia, C. A novel marine traffic safety assessment based on cloud models. Technol. Comput. Sci. 2010, 3, 60-63.

29. Li, J.; Wang, M.; Xu, P.; Xu, P. Classification of stability of surrounding rock using cloud model. Chin. J. Geotech. Eng. 2014, 36, 83-87.

30. Kavousi-Fard, A.; Niknam, T.; Fotuhi-Firuzabad, M. A novel stochastic framework based on cloud theory and h-modified bat algorithm to solve the distribution feeder reconfiguration. IEEE Trans. Smart Grid 2016, 7, 740-750. [CrossRef]

31. Wang, X.T.; Li, S.C.; Xu, Z.H.; Hu, J.; Pan, D.D.; Xue, Y.G. Risk assessment of water inrush in karst tunnels excavation based on normal cloud model. Bull. Eng. Geol. Environ. 2019. [CrossRef]

32. Zhang, L.; Wu, X.; Chen, Q.; Skibniewski, M.J.; Zhong, J. Developing a cloud model based risk assessment methodology for tunnel-induced damage to existing pipelines. Stoch. Environ. Res. Risk Assess. 2015, 29, 513-526. [CrossRef]

33. GB8537-1995 Standards of Natural Mineral Water for Drinking; Standards Press of China: Beijing, China, 1995.

34. GB5749-2006 Hygienic Standards of Water for Drinking; Standards Press of China: Beijing, China, 2006. 
35. Zhou, Z.; Shucai, L.I.; Liping, L.I.; Wei, L.U.; Shi, S. Attribute recognition model of surrounding rock optimized classification and its engineering application. J. Cent. South Univ. 2013, 44, 1611-1619.

36. Huang, H.; Lu, J. Identification of river water pollution characteristics based on projection pursuit and factor analysis. Environ. Earth Sci. 2014, 72, 3409-3417. [CrossRef]

37. Xiao, F.; Chen, J. Fractal projection pursuit classification model applied to geochemical survey data. Comput. Geosci. 2012, 45, 75-81. [CrossRef]

38. Wang, X.; Zhang, Y.; Jiao, J. Application of ppc model based on raga in bidding evaluation of engineering construction project. Decis. Support Syst. 2011, 3, 299-306.

39. Sun, H.; Wang, S.; Hao, X. An Improved Analytic Hierarchy Process Method for the evaluation of agricultural water management in irrigation districts of north China. Agric. Water Manag. 2017, 179, 324-337. [CrossRef]

40. Ma, S.L.; Ye, D.Y. Research on computing minimum entropy based attribute reduction via stochastic optimization algorithms. Moshi Shibie Yu Rengong Zhineng Pattern Recognit. Artif. Intell. 2012, 25, 96-104.

41. Zhou, J.; Li, X.; Peng, X.; Qi, L. Analysis of the Examination Result of the Quality of Spring Water in Jinan City. Prev. Med. 2009, 15, 522-524.

42. Cui, L.L.; Liu, C.; Wang, S. Investigation of spring water quality in Jinan. Chin. J. Public Health Adm. 2010, 26, 404-406.

43. Luo, X.Q.; Zhang, Q.; Chen, L.Y.; Meng, Q.X.; Zhao, M. Nanming river upstream region comprehensive quality evaluation in guiyang based on the single factor index method. Ground Water 2016, 38, 80-82.

44. Zhu, M.; Li, Y.; Li, J.; Yang, L. A Nemerow Index and Vague Sets Integrated Water Quality Comprehensive Assessment Model. In Proceedings of the 4th International Conference in Bioinformatics and Biomedical Engineering, Chengdu, China, 18-20 June 2010; pp. 1-4.

(C) 2019 by the authors. Licensee MDPI, Basel, Switzerland. This article is an open access article distributed under the terms and conditions of the Creative Commons Attribution (CC BY) license (http://creativecommons.org/licenses/by/4.0/). 